\title{
Visual impairment in the 40- to 64-year-old population of Shahroud, Iran
}

H Hashemi ${ }^{1,2}$, M Khabazkhoob ${ }^{1}$, MH Emamian ${ }^{3}$, M Shariati ${ }^{4}$ and A Fotouhi ${ }^{5}$

\begin{abstract}
Purpose To determine the prevalence of visual impairment by age and gender in Shahroud.

Methods Using random cluster sampling, 6311 Shahroud inhabitants who were between 40 and 64 years old were invited for ophthalmological examinations. Visual acuity worse
\end{abstract} than 0.5 LogMAR (20/60) and 1.3 LogMAR (20/ 400 ) in the better eye was regarded as low vision and blindness, respectively. The cause of blindness was determined by an ophthalmologist and in a person with more than one cause, the most correctable cause was regarded as the main cause.

Results This study was conducted on 5190 participants (response rate: $82.2 \%$ ). On the basis of presenting visual acuity, the prevalence of low vision and blindness was found to be $1.8 \%$ (95\% confidence interval (CI): 1.4-2.10) and 0.5\% (95\% CI: 0.3-0.7), respectively. Based on corrected vision, these values were $0.5 \%(95 \% \mathrm{CI}: 0.3-0.7)$ and 0.3\% (95\% CI: $0.1-0.4$ ), respectively. Visual impairment increased with age in women $(P<0.001)$. Uncorrected refractive errors $(63.9 \%)$, cataract $(20.2 \%)$, and amblyopia $(5.9 \%)$ were the most common causes of visual impairment based on presenting vision. Based on corrected vision, however, cataract $(42.5 \%)$, amblyopia $(12.5 \%)$, and retinitis pigmentosa $(\mathbf{7 . 5 \%})$ were the most common causes of visual impairment. Conclusion Although the prevalence of visual impairment in the city of Shahroud was determined to be lower than two previous studies in the country, correction of refractive errors and cataract could minimize the rate of visual impairment in this population as they were shown to comprise $85 \%$ of the causes of visual impairment. The elderly women need to receive more attention.
Eye (2012) 26, 1071-1077; doi:10.1038/eye.2012.94; published online 18 May 2012

Keywords: determinants; population-based study; prevalence; Shahroud; visual impairment

\section{Introduction}

Latest reports show that 161 million individuals have visual impairment based on best-corrected visual impairment (BCVA) and 259 million people are visually impaired based on BCVA and presenting vision, worldwide. ${ }^{1,2}$ On the basis of available reports, Asian countries, especially South and East Asian countries, have a high prevalence of visual impairment. ${ }^{3}$ The prevalence of visual impairments, especially blindness, varies from $0.5 \%$ in Singapore to $12 \%$ in India. ${ }^{3}$ Published papers on the status of visual impairments in different countries reveal that these impairments are problematic in developed countries, as well as developing ones. ${ }^{4,5}$ Cataract, as the primary cause of blindness, is responsible for $50 \%$ of the cases of blindness, especially in Asian, African, and South American countries. However, reports from western countries indicate that AMD and glaucoma are the main causes of blindness in these countries. 5,6

In the Middle East, there are valuable reports from Pakistan, ${ }^{7-9}$ Sudan, ${ }^{10}$ Turkey, ${ }^{11}$ and Iran. ${ }^{12}$

Although many studies have been performed on ocular diseases in the Middle East in the recent years, they are not comparable in quantity with studies performed in East Asian countries.

Iran, among Middle East countries, has a relatively large population. To date, two papers have been published on visual impairments in Iran. ${ }^{12,13}$ Although one of them was performed
${ }^{1}$ Noor Ophthalmology Research Center, Noor Eye Hospital, Tehran, Iran

${ }^{2}$ Farabi Eye Hospital, Tehran University of Medical Sciences, Tehran, Iran

${ }^{3}$ Shahroud University of Medical Sciences, Shahroud, Iran

${ }^{4}$ Education Development Center, Tehran University of Medical Sciences, Tehran, Iran

${ }^{5}$ Department of Epidemiology and Biostatistics, School of Public Health, Tehran University of Medical Sciences, Tehran, Iran

Correspondence: A Fotouhi, Department of Epidemiology and Biostatistics, School of Public Health, Tehran University of Medical Sciences,

Tehran 14155-6446, Iran Tel: +98 2188987381 ; Fax: +98 2188987382 . E-mail: afotouhi@tums.ac.ir

Received: 19 August 2011 Accepted in revised form: 8 January 2012 Published online: 18 May 2012 
in Tehran, the capital city of Iran, and the nonhomogeneity of the samples resulted in more generalizable findings for Iran, ${ }^{12}$ some factors have made grounds for further work in this regard.

First, the population of Iran is rather old and attention to visual impairments is more important as compared with the previous decade. Second, with regard to improvements in ophthalmological and optometric services in the world and in Iran, we expect lower rates of visual impairments. Finally, considering demographic changes, ophthalmological advancements and even changes in the lifestyle, periodic studies seem necessary in different parts of the world. Considering the abovementioned reasons, conducting another epidemiological study with more comprehensive objectives was necessary. The Shahroud study, which was designed as a cohort study, contained valuable information on different ocular indices. In the present report, which has been written based on the data of the first phase of this study, which was conducted between 2009 and 2010, we have discussed the prevalence of visual impairments and their determinants in the population of Shahroud.

\section{Materials and methods}

Geographically, Shahroud is located in the north east of Iran. According to the 2006 census, the population of Shahroud is 133835 . The target population in this study was Shahroud inhabitants between the ages of 40 and 64 years. Three hundred clusters were selected, each cluster consisting of sufficient number of households to provide a total of at least 20 eligible persons. As the population of Shahroud is covered by nine health centres in the Iranian Primary Health Care system, each centre was considered as a stratum and the number of the clusters was calculated proportionate to the population of each centre. The electronic databases of the health centres provided the sampling frame (complete listing of all households) for each stratum. A systematic sampling procedure was used to select the index households for each cluster.

After identification of the index household in each cluster, the enumeration of the neighbouring households continued from the right side of that household in the cluster until at least 20 eligible individuals were found. As all the 40- to 64-year-old members of the households entered the study, depending on the number of the eligible individuals in the last household, the cluster included at least 20 individuals.

In a door-to-door visit, expert interviewers persuaded 40- to 64-year-old members of families to receive eye examinations and after completing the preliminary information form upon their agreement, gave them an invitation letter. Before including individuals in the study, they first received information on the project and were then interviewed. In the interview, demographic data, occupation status, socioeconomic status, history of cigarette smoking, and medical, ophthalmological, and medication history were evaluated.

\section{Examinations}

Extensive optometric and ophthalmological examinations were performed for each participant with especial focus on visual acuity and refraction measurements.

To measure visual acuity, the LogMAR chart was at $4 \mathrm{~m}$, and the participant was asked to read the letters starting from the topmost row down. If someone was unable to read the topmost row, visual acuity was determined to be 'counting finger' if (s)he could count the number of held-up fingers at $3 \mathrm{~m}$. The term 'hand motion' was applied if the patient was unable to count fingers but could distinguish a hand if it was moving or not in front of his/her face and the term 'light perception' was used if the participant could perceive any light. In the next step, using a Topcon AR 8800 autorefractometer (Topcon Corporation, Tokyo, Japan), refraction was tested for all participants and based on this refraction, objective and subjective refraction tests were also performed on them. Using collected data, BCVA was measured.

Ophthalmological examinations were performed before and after pupil dilation. Before pupil dilation, measurement of intraocular pressure and slit lamp biomicroscopy were carried out and after dilation, clinical lens opacity grading, evaluation of vitreous opacity, slit lamp examinations, and retinal examinations using direct and indirect ophthalmoscopy were performed. In the end, the ophthalmologist determined the existence of any refractive error in the participant and its cause as his/her diagnosis.

\section{Definitions}

We adopted the definitions of WHO in conducting this study. ${ }^{14}$ Visual impairment included low vision and blindness and was reported as Presenting Visual Acuity (PVA) and BCVA.

Low vision was defined as visual acuity between 0.5 $\operatorname{LogMAR}(20 / 60)$ and $\leq 1.3 \operatorname{LogMAR}(20 / 400)$ in the better eye and blindness was visual acuity worse than 1.3 LogMAR $(20 / 400)$ in the better eye. If a patient was found to have more than one cause for his/her visual impairment, or the reason for the visual impairment was different for each eye in one participant, the most correctable reason was regarded as the reason for visual impairment. 


\section{Statistical analysis}

We used the percentage of the visual impairment along with its $95 \%$ confidence interval (CI) for reporting their prevalence and to calculate the $95 \% \mathrm{CI}$, the design effect was regarded. To detect relationships between the evaluated variables and visual impairment, blindness, and low vision, multiple logistic regression was employed. If the prevalence was low and the distribution was not normal, binominal distribution was used to calculate the $95 \% \mathrm{CI}$.

\section{Ethical considerations}

All participants signed the informed written consent in the presence of a witness. The study protocol was approved by the Ethics Committee of Shahroud University of Medical Sciences.

\section{Results}

Of 6311 invited individuals, 5190 participated in the study (response rate $=82.2 \%$ ). Of all the participants, $57.4 \%(n=2977)$ were female and the mean $( \pm$ SD) age of the participants was $50.9 \pm 6.2$ years.

\section{Presenting visual acuity}

Table 1 shows the prevalence of low vision, blindness, and visual impairment by age and gender. The prevalence of low vision and blindness was $1.8 \%$
(95\% CI: 1.4-2.1) and 0.5\% (95\% CI: 0.3-0.7), respectively. In general, the prevalence of visual impairment based on PVA, including low vision and blindness, was $2.3 \%$ (95\% CI: 1.9-2.7). The prevalence of low vision was $1.3 \%$ in men and $2.1 \%$ in women $(P=0.027)$.

Multiple regression model showed that the prevalence of low vision increased with age $(P<0.001)$, and that its prevalence was significantly higher in women $(P<0.001)$. Blindness did not have a significant difference between genders $(P=0.432)$; however, it was noted that blindness increased significantly with age in women; there were no cases of blindness in 40- to 44-year-old women whereas $1.3 \%$ of the women aged 60 and above were blind. For each year increase in women's age, the odds of blindness increased by $18 \%(P<0.001)$. In men, the prevalence of blindness was $0.31 \%$ in individuals aged between 40 and 44 , and $0.34 \%$ in individuals aged 60 and above $(P=0.172)$. Overall, the difference in the prevalence of visual impairments was not significant between genders $(P=0.112)$; however, it was noted that visual impairments increased significantly in women with age $(P<0.001)$ while there was no significant relationship $(P=0.375)$ between age and visual impairments in men (Figure 1a).

\section{Best-corrected visual acuity}

The prevalence of low vision was $0.5 \%$ (95\% CI: $0.3-0.7$ ) based on corrected vision. Table 1 shows the prevalence of visual impairment by age and gender. There was no significant difference in the prevalence of low vision

Table 1 Prevalence of visual impairment (low vision and blindness) by age and gender

\begin{tabular}{|c|c|c|c|c|c|c|c|c|}
\hline & \multicolumn{4}{|c|}{ Presenting visual acuity } & \multicolumn{4}{|c|}{ Best corrected visual acuity } \\
\hline & $\mathrm{n}$ & $\begin{array}{l}\text { Low vision } \\
\%(95 \% \mathrm{CI})\end{array}$ & $\begin{array}{l}\text { Blindness } \\
\%(95 \% \mathrm{CI})\end{array}$ & $\begin{array}{l}\text { Visual impairment } \\
\%(95 \% \mathrm{CI})\end{array}$ & $\mathrm{n}$ & $\begin{array}{l}\text { Low vision } \\
\%(95 \% \mathrm{CI})\end{array}$ & $\begin{array}{l}\text { Blindness } \\
\%(95 \% \mathrm{CI})\end{array}$ & $\begin{array}{c}\text { Visual impairment } \\
\%(95 \% \mathrm{CI})\end{array}$ \\
\hline \multicolumn{9}{|l|}{ Age groups } \\
\hline $40-44$ & 960 & $1.5(0.7-2.3)$ & $0.1(0.01-0.7)^{\mathrm{a}}$ & $1.6(0.7-2.4)$ & 960 & $0.2(0.05-0.8)^{a}$ & 0 & $0.2(0.1-0.8)^{\mathrm{a}}$ \\
\hline $45-49$ & 1389 & $0.9(0.4-1.4)$ & $0.6(0.2-1.0)$ & $1.5(0.8-2.2)$ & 1388 & $0.3(0.0-0.6)$ & $0.4(0.0-0.7)$ & $0.6(0.2-1.1)$ \\
\hline $50-54$ & 1285 & $1.5(0.8-2.2)$ & $0.5(0.1-0.9)$ & $2.0(1.2-2.8)$ & 1285 & $0.4(0.0-0.7)$ & $0.2(0.0-0.5)$ & $0.6(0.2-1.1)$ \\
\hline $55-59$ & 953 & $1.9(1.0-2.8)$ & $0.7(0.2-1.3)$ & $2.6(1.6-3.7)$ & 953 & $0.8(0.3-1.4)$ & $0.3(0.0-0.7)$ & $1.2(0.5-1.8)$ \\
\hline $60-64$ & 601 & $4.5(2.9-6.1)$ & $0.8(0.1-1.6)$ & $5.3(3.6-7.0)$ & 600 & $1.3(0.4-2.2)$ & $0.3(0.08-1.3)^{\mathrm{a}}$ & $1.7(0.6-2.7)$ \\
\hline \multicolumn{9}{|l|}{ Gender } \\
\hline Male & 2212 & $1.3(0.8-1.7)$ & $0.6(0.3-1.0)$ & $1.9(1.3-2.5)$ & 2211 & $0.5(0.2-0.8)$ & $0.3(0.1-0.5)$ & $0.8(0.4-1.2)$ \\
\hline Female & 2976 & $2.1(1.6-2.6)$ & $0.5(0.2-0.7)$ & $2.6(2.0-3.1)$ & 2975 & $0.5(0.3-0.8)$ & $0.2(0.0-0.4)$ & $0.7(0.4-1.0)$ \\
\hline Crude total & 5188 & $1.8(1.4-2.1)$ & $0.5(0.3-0.7)$ & $2.3(1.9-2.7)$ & 5186 & $0.5(0.3-0.7)$ & $0.3(0.1-0.4)$ & $0.8(0.5-1.0)$ \\
\hline \multicolumn{9}{|l|}{ Age standardized ${ }^{\mathrm{b}}$} \\
\hline $\begin{array}{l}\text { Age and gender } \\
\text { standardized total }^{b}\end{array}$ & 5188 & $1.6(1.3-2.0)$ & $0.5(0.3-0.7)$ & $2.1(1.7-2.5)$ & 5186 & $0.5(0.3-0.7)$ & $0.2(0.1-0.4)$ & $0.7(0.5-0.9)$ \\
\hline Design effect & & 0.95 & 0.92 & 1.03 & & 0.91 & 0.96 & 0.97 \\
\hline
\end{tabular}

Abbreviation: $\mathrm{CI}$, confidence interval.

a $95 \%$ CI calculated by binomial distribution.

${ }^{\mathrm{b}}$ The Shahroud population is considered as the standard population. 
between genders $(P=0.844)$. There was a significant interaction between age and gender in the prevalence of low vision; the prevalence of low vision increased significantly with age in women $(P<0.001, \mathrm{OR}=1.18$, 95\% CI: 1.08-1.30), whereas no relationship with age was detected in men $(P=0.341)$. In general, there were 13 cases of blindness in this study and the prevalence of blindness was calculated to be $0.3 \%$ (95\% CI: 0.1-0.4). Table 1 shows the distribution of blind participants by gender and age group. Although the prevalence of blindness did not have a significant difference between genders according to the multiple logistic regression model $(P=0.696)$ and did not significantly correlate with age $(P=0.133)$, it was significantly more prevalent in the elderly women $(P<0.001)$. Our findings showed that there were no cases of blindness in women under the age of 50 while in the age groups 50-54,55-59, and $\geq 60$, the prevalence of blindness was $0.3 \%, 0.4 \%$, and $0.6 \%$ in women, respectively. In men, in the age groups 45-49, 50-54, and 55-59, the prevalence of blindness was found to be $0.9 \%, 0.2 \%$, and $0.2 \%$, respectively. Overall, the prevalence of visual impairment based on corrected vision was $0.8 \%$ (95\% CI: 0.5-1.0) with no difference between genders $(P=0.856)$; however, visual impairment increased significantly $(P<0.001)$ in women with age (Figure 1b).

Table 2 shows the causes of visual impairment based on presenting and corrected vision. As this table shows, based on the presenting vision, the most common causes of visual impairment were uncorrected refractive error and cataract. The causes of blindness based on the corrected vision were cataract and amblyopia.
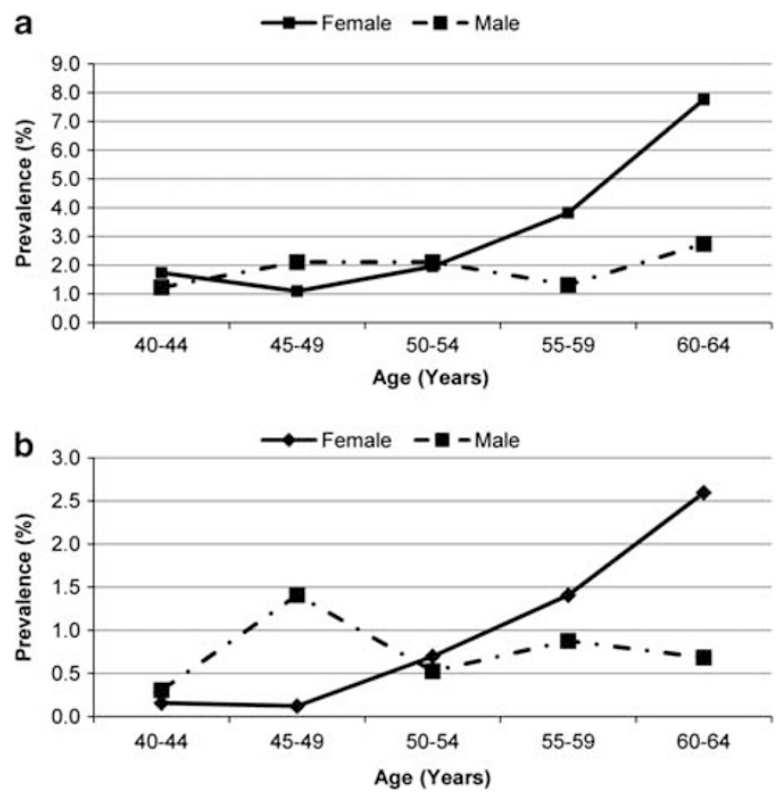

Figure 1 Prevalence of visual impairment by age and gender; (a) PVA and (b) BCVA.
Also, Table 3 shows different types of ocular problems, in combination, in individuals with visual impairment. As this table shows, $38.1 \%$ of the visual impairments are only due to refractive errors followed by $11 \%$ caused by cataract.

\section{Discussion}

In this report, we observed low prevalence of visual impairment and blindness and justified it by recent

Table 2 Causes of visual impairment in the participants based on presenting and best corrected vision

\begin{tabular}{|c|c|c|c|c|}
\hline \multirow[t]{2}{*}{ Causes of visual impairment } & \multicolumn{2}{|c|}{$\begin{array}{l}\text { Presenting } \\
\text { visual acuity }\end{array}$} & \multicolumn{2}{|c|}{$\begin{array}{l}\text { Best corrected } \\
\text { visual acuity }\end{array}$} \\
\hline & $\mathrm{n}$ & $\%$ & $\mathrm{n}$ & $\%$ \\
\hline Uncorrected refractive error & $75^{\mathrm{a}}$ & 63.9 & 0 & - \\
\hline Cataract & $24^{\mathrm{b}}$ & 20.2 & 17 & 42.5 \\
\hline Corneal opacity & 1 & 0.8 & 2 & 5.0 \\
\hline Chorioretinal atrophy & 2 & 1.7 & 1 & 2.5 \\
\hline Retinitis pigmentosa & 3 & 2.5 & 3 & 7.5 \\
\hline Macular oedema & 2 & 1.7 & 0 & 0 \\
\hline Albinism & 1 & 0.8 & 2 & 5.0 \\
\hline Optic atrophy & 1 & 0.8 & 3 & 7.5 \\
\hline Amblyopia & 7 & 5.9 & 5 & 12.5 \\
\hline Keratoconus & 0 & 0 & 2 & 5.0 \\
\hline Macular atrophy & 0 & 0 & 1 & 2.5 \\
\hline Other & 2 & 1.7 & 4 & 10.0 \\
\hline Total & 118 & 100 & 40 & 100 \\
\hline
\end{tabular}

a Three cases had pseudophakia.

b Two cases had pseudophakia.

Table 3 Types of visual and ocular problems in individuals with visual impairment based on the presenting vision

\begin{tabular}{|c|c|c|}
\hline & Frequency & Percent \\
\hline Uncorrected refractive error & 45 & 38.1 \\
\hline Cataract & 13 & 11.0 \\
\hline Uncorrected refractive error + cataract & 10 & 8.5 \\
\hline Uncorrected refractive error + amblyopia & 9 & 7.6 \\
\hline Amblyopia & 7 & 5.9 \\
\hline Cataract + diabetic retinopathy & 4 & 3.4 \\
\hline Retinitis pigmentosa & 3 & 2.5 \\
\hline Uncorrected refractive error + unknown & 2 & 1.7 \\
\hline Chorioretinal atrophy & 2 & 1.7 \\
\hline Uncorrected refractive error + keratoconus & 2 & 1.7 \\
\hline Uncorrected refractive error + corneal opacity & 2 & 1.7 \\
\hline Cataract + retinitis pigmentosa & 2 & 1.7 \\
\hline Cataract + chorioretinal atrophy & 2 & 1.7 \\
\hline Albinism & 1 & 0.8 \\
\hline Macular oedema & 1 & 0.8 \\
\hline Macular oedema + macular atrophy & 1 & 0.8 \\
\hline Uncorrected refractive error + albinism & 1 & 0.8 \\
\hline Optic atrophy & 1 & 0.8 \\
\hline Corneal opacity & 1 & 0.8 \\
\hline Uncorrected refractive error + optic atrophy & 1 & 0.8 \\
\hline Cataract + amblyopia & 1 & 0.8 \\
\hline Cataract + corneal opacity & 1 & 0.8 \\
\hline $\begin{array}{l}\text { Uncorrected refractive error }+ \text { cataract }+ \\
\text { glaucoma }\end{array}$ & 1 & 0.8 \\
\hline $\begin{array}{l}\text { Uncorrected refractive error }+ \text { cataract }+ \\
\text { diabetic retinopathy }\end{array}$ & 1 & 0.8 \\
\hline $\begin{array}{l}\text { Uncorrected refractive error }+ \text { amblyopia }+ \\
\text { optic atrophy }\end{array}$ & 1 & 0.8 \\
\hline Cataract + glaucoma + diabetic retinopathy & 1 & 0.8 \\
\hline Unknown & 2 & 1.7 \\
\hline Total & 118 & 100 \\
\hline
\end{tabular}


advancements, especially in cataract surgery rate, especially in cataract surgery rate, but still reported cataract as the primary cause of visual impairment. On the other hand, based on the presenting vision, we found that uncorrected refractive errors were the leading cause of visual impairment. It seems that the main reason for these findings is the age range of the participants as diseases like AMD generally develop after the age 60 while our study population was more prone to cataract. Therefore, the finding that cataract is the primary cause of visual impairment based on corrected vision does not necessarily mean inadequate health services.

To date, two studies (Tehran and Zahedan) have been published on visual impairments in Iran ${ }^{12,13}$ but less than $50 \%$ of the participants were above 40 years of age in these two studies. As visual impairments mostly affect individuals above 40 years old, the present study provided us with valuable information about visual impairment in the 40- to 64-year-old population of Shahroud with a rather large sample size.

In different reports, visual impairment has been presented based on WHO and USA definitions. According to the USA definition, visual acuity less than $20 / 40$ in the worse eye is considered visual impairment while according to $\mathrm{WHO}$, visual impairment is defined as visual acuity less than 20/60 in the worse eye; therefore, care must be taken while comparing the findings of different reports.

In this report, in addition to presenting visual impairment based on corrected vision, we reported the results of visual impairment according to presenting vision. It seems that visual impairment based on presenting vision not only shows the extent of the problem but also delineates the percentage of the people with correctable visual impairment who, for any reason, live with it uncorrected.

As mentioned earlier, the prevalence of visual impairment was 0.8 and $2.3 \%$ and the prevalence of blindness was 0.3 and $0.5 \%$ according to corrected and presenting vision, respectively. For correct comparison with the findings of Tehran and Zahedan studies, ${ }^{12,13}$ we reported the results of visual impairment in 40- to 59-year-old participants, similar to Tehran and Zahedan studies. In Tehran and Zahedan studies, visual impairment according to the corrected vision in the age group $40-59$ was $1.3 \%$ and $9.4 \%$, respectively.

The prevalence of the visual impairment in this age group (standardized for age and gender) according to the corrected vision was $0.6 \%$. This comparison also shows that the inhabitants of Shahroud are less affected by visual impairment than the inhabitants of Tehran and Zahedan. ${ }^{12,13}$

Regarding Zahedan, it should be kept in mind that this city is one of the weakest cities of Iran in terms of several health indices. In general, the better socioeconomic status of Shahroud may be one of the reasons of the low prevalence of visual impairment in this city. Moreover, this study was conducted 9 years after Tehran and 5 years after Zahedan studies. With regard to the fact that CSR increased 2.5 fold between 2000 and 2005, 14 improvements in ophthalmological services can be of the reasons of this difference.

According to our literature review, the report from Malaysia is one of the few studies with a similar population age range as our study; the prevalence of blindness did not differ significantly between our study and the study conducted in Malaysia. ${ }^{15}$

We expected a strong correlation between age and visual impairment but as mentioned earlier, this relationship was only observed in women. In men, visual impairment did not have a significant relationship with age. Blindness and visual impairment has been reported to be higher in women in studies conducted in India, 16 Rotterdam, ${ }^{6}$ Melbourne, ${ }^{17}$ Oman, ${ }^{18}$ and Meiktila. ${ }^{19}$ On the other hand, some studies have reported blindness and visual impairment to be higher in men. ${ }^{20}$ Some factors should be considered in this regard. Similar to some studies, ${ }^{21-23}$ we also believe that women's access to health services has improved in recent decades; therefore, younger women now utilize such services as men do. However, older women have less utilized health and medical care services.

According to the presenting vision, refractive errors were the cause of the visual impairment in $63.9 \%$ of the cases. Similarly, many studies have reported refractive errors as one of the two major causes of the visual impairment. ${ }^{24-28}$ However, the results of these studies indicate that visual impairment because of uncorrected refractive errors was considerably high in our study, even higher than Tehran and Zahedan studies. ${ }^{12,13}$

Considering the fact that the prevalence of the visual impairment in our study was $0.8 \%$ and $2.3 \%$, respectively, $1.5 \%$ of the participants could prevent from visual impairment by correcting their PVA. The $0.8 \%$ of the population who still have visual impairment after correcting refractive errors should either receive surgical intervention or get used to their visual impairment. However, 75 participants in this study (1.5\%) could simply achieve normal vision by correcting their refractive error. In 2004, Resnikoff et $a^{2}$ reported that 161 million individuals had visual impairment worldwide. In another report in 2006, Dandona et al ${ }^{1}$ reported that considering the cases of uncorrected refractive errors, the number of the individuals with visual impairment was underestimated by $61 \%$ or 98 million people. Comparison of our study with the two aforementioned shows that if we do not report visual impairment according to the presenting vision $(2.3 \%)$, the prevalence of the visual 
impairment $(0.8 \%)$ is underestimated by $\sim 190 \%$. However, attention must be paid that about $20 \%$ of the cases of visual impairment according to presenting vision were due to cataract. Other studies have reported a higher proportion for cataract. ${ }^{27-32}$ Overall, based on the presenting vision, about $84 \%$ of the cases of visual impairment and $64 \%$ of the cases of blindness can be simply prevented by cataract surgery or correcting refractive errors, which is important in terms of public health.

On the basis of the corrected vision, cataract was the leading cause of visual impairment and blindness in our study. In most reports, especially from East Asian countries, cataract has been introduced as the first cause of visual impairment. ${ }^{14,27,33,34}$ In some reports like Harbin from China, ${ }^{34}$ it has been shown that cataract is responsible for $70 \%$ of the cases of bilateral blindness.

Although cataract is still the most important cause of visual impairment in East Asian countries, available reports suggest $A M D$ as the primary cause in western countries $^{6,35,36}$ in a way that AMD has been reported to be the cause of visual impairment in more than $50 \%$ of the cases. ${ }^{36}$

In conclusion, the prevalence of visual impairment in Shahroud was lower than prevalence rates reported by two previous studies in Iran. Our results showed that correcting refractive errors and cataract could decrease the burden of visual impairment according to the presenting vision by $85 \%$. Attention to these two problems (refractive errors and cataract) and correcting them also substantially contribute to prevention from visual impairment and blindness. Moreover, it is important that the elderly women, as the at-risk population, receive special care and attention.

\section{Summary}

What was known before

- On the basis of available reports, Asian countries, especially South and East Asian countries, have a high prevalence of visual impairment.

- The prevalence of visual impairments, especially blindness, varies from $0.5 \%$ in Singapore to $12 \%$ in India.

- In the present report, we have discussed the prevalence of visual impairments and their determinants in the population of Shahroud, North of Iran.

What this study adds

- The prevalence of visual impairment in the city of Shahroud was determined to be lower than most studies in the region.

- Refractive errors and cataract were shown to comprise $85 \%$ of the causes of visual impairment in the population.

\section{Conflict of interest}

The authors declare no conflict of interest.

\section{Acknowledgements}

This project was supported by Noor Ophthalmology Research Centre, Shahroud University of Medical Sciences and Tehran University of Medical Sciences.

\section{References}

1 Dandona L, Dandona R. What is the global burden of visual impairment? BMC Med 2006; 4: 6 .

2 Resnikoff S, Pascolini D, Etya'ale D, Kocur I, Pararajasegaram R, Pokharel GP et al. Global data on visual impairment in the year 2002. Bull World Health Organ 2004; 82: 844-851.

3 Wong TY, Loon SC, Saw SM. The epidemiology of age related eye diseases in Asia. Br J Ophthalmol 2006; 90: 506-511.

4 Buch H, Vinding T, la CM, Appleyard M, Jensen GB, Nielsen NV. Prevalence and causes of visual impairment and blindness among 9980 Scandinavian adults: the Copenhagen City Eye Study. Ophthalmology 2004; 111: 53-61.

5 Congdon N, O'Colmain B, Klaver CC, Klein R, Munoz B, Friedman DS et al. Causes and prevalence of visual impairment among adults in the United States. Arch Ophthalmol 2004; 122: 477-485.

6 Klaver CC, Wolfs RC, Vingerling JR, Hofman A, de Jong PT. Age-specific prevalence and causes of blindness and visual impairment in an older population: the Rotterdam Study. Arch Ophthalmol 1998; 116: 653-658.

7 Ahmad K, Khan MD, Qureshi MB, Munami S, Shah RA, Rasheed $\mathrm{H}$ et al. Prevalence and causes of blindness and low vision in a rural setting in Pakistan. Ophthalmic Epidemiol 2005; 12: 19-23.

8 Dineen B, Bourne RR, Jadoon Z, Shah SP, Khan MA, Foster A et al. Causes of blindness and visual impairment in Pakistan. The Pakistan national blindness and visual impairment survey. Br J Ophthalmol 2007; 91: 1005-1010.

9 Jadoon MZ, Dineen B, Bourne RR, Shah SP, Khan MA, Johnson GJ et al. Prevalence of blindness and visual impairment in Pakistan: the Pakistan National Blindness and Visual Impairment Survey. Invest Ophthalmol Vis Sci 2006; 47: 4749-4755.

10 Ngondi J, Ole-Sempele F, Onsarigo A, Matende I, Baba S, Reacher $\mathrm{M}$ et al. Prevalence and causes of blindness and low vision in southern Sudan. PLoS Med 2006; 3: e477.

11 Negrel AD, Minassian DC, Sayek F. Blindness and low vision in southeast Turkey. Ophthalmic Epidemiol 1996; 3: 127-134.

12 Fotouhi A, Hashemi H, Mohammad K, Jalali KH. The prevalence and causes of visual impairment in Tehran: the Tehran Eye Study. Br J Ophthalmol 2004; 88: 740-745.

13 Shahriari HA, Izadi S, Rouhani MR, Ghasemzadeh F, Maleki AR. Prevalence and causes of visual impairment and blindness in Sistan-va-Baluchestan Province, Iran: Zahedan Eye Study. Br J Ophthalmol 2007; 91: 579-584.

14 Hashemi H, Alipour F, Mehravaran S, Rezvan F, Fotouhi A, Alaedini F. Five Year Cataract Surgical Rate in Iran. Optom Vis Sci 2009; 86: 890-894.

15 Zainal M, Ismail SM, Ropilah AR, Elias H, Arumugam G, Alias D et al. Prevalence of blindness and low vision in Malaysian population: results from the National Eye Survey 1996. Br J Ophthalmol 2002; 86: 951-956. 
16 Dandona R, Dandona L, Srinivas M, Giridhar P, Prasad MN Vilas $\mathrm{K}$ et al. Moderate visual impairment in India: the Andhra Pradesh Eye Disease Study. Br J Ophthalmol 2002; 86: 373-377.

17 Taylor HR, Livingston PM, Stanislavsky YL, McCarty CA. Visual impairment in Australia: distance visual acuity, near vision, and visual field findings of the Melbourne Visual Impairment Project. Am J Ophthalmol 1997; 123: 328-337.

18 Khandekar R, Mohammed AJ, Negrel AD, Riyami AA. The prevalence and causes of blindness in the Sultanate of Oman: the Oman Eye Study (OES). Br J Ophthalmol 2002; 86: 957-962.

19 Casson RJ, Newland HS, Muecke J, McGovern S, Durkin S, Sullivan Tet al. Prevalence and causes of visual impairment in rural myanmar: the Meiktila Eye Study. Ophthalmology 2007; 114: 2302-2308.

20 Hyman L, Wu SY, Connell AM, Schachat A, Nemesure B, Hennis A et al. Prevalence and causes of visual impairment in The Barbados Eye Study. Ophthalmology 2001; 108: 1751-1756.

21 Athanasiov PA, Edussuriya K, Senaratne T, Sennanayake S, Selva D, Casson RJ. Cataract in central Sri Lanka: cataract surgical coverage and self-reported barriers to cataract surgery. Clin Experiment Ophthalmol 2009; 37: 780-784.

22 Athanasiov PA, Casson RJ, Newland HS, Shein WK, Muecke JS, Selva D et al. Cataract surgical coverage and self-reported barriers to cataract surgery in a rural Myanmar population. Clin Experiment Ophthalmol 2008; 36: 521-525.

23 Lewallen S, Mousa A, Bassett K, Courtright P. Cataract surgical coverage remains lower in women. $\mathrm{Br} J$ Ophthalmol 2009; 93: 295-298.

24 Michon JJ, Lau J, Chan WS, Ellwein LB. Prevalence of visual impairment, blindness, and cataract surgery in the Hong Kong elderly. Br J Ophthalmol 2002; 86: 133-139.

25 Oye JE, Kuper H, Dineen B, Befidi-Mengue R, Foster A. Prevalence and causes of blindness and visual impairment in Muyuka: a rural health district in South West Province, Cameroon. Br J Ophthalmol 2006; 90: 538-542.

26 Dineen BP, Bourne RR, Ali SM, Huq DM, Johnson GJ. Prevalence and causes of blindness and visual impairment in Bangladeshi adults: results of the National Blindness and Low Vision Survey of Bangladesh. Br J Ophthalmol 2003; 87: 820-828.

27 See JL, Wong TY, Yeo KT. Trends in the pattern of blindness and major ocular diseases in Singapore and Asia. Ann Acad Med Singapore 1998; 27: 540-546.

28 Thulasiraj RD, Nirmalan PK, Ramakrishnan R, Krishnadas R, Manimekalai TK, Baburajan NP et al. Blindness and vision impairment in a rural south Indian population: the Aravind Comprehensive Eye Survey. Ophthalmology 2003; 110: 1491-1498.

29 Pokharel GP, Regmi G, Shrestha SK, Negrel AD, Ellwein LB. Prevalence of blindness and cataract surgery in Nepal. Br J Ophthalmol 1998; 82: 600-605.

30 Nirmalan PK, Thulasiraj RD, Maneksha V, Rahmathullah R, Ramakrishnan R, Padmavathi A et al. A population based eye survey of older adults in Tirunelveli district of south India: blindness, cataract surgery, and visual outcomes. Br J Ophthalmol 2002; 86: 505-512.

31 Dunzhu S, Wang FS, Courtright P, Liu L, Tenzing C, Noertjojo $\mathrm{K}$ et al. Blindness and eye diseases in Tibet: findings from a randomised, population based survey. Br J Ophthalmol 2003; 87: 1443-1448.

32 Oye JE, Kuper H. Prevalence and causes of blindness and visual impairment in Limbe urban area, South West Province, Cameroon. Br J Ophthalmol 2007; 91: 1435-1439.

33 Zainal M, Ismail SM, Ropilah AR, Elias H, Arumugam G, Alias D et al. Prevalence of blindness and low vision in Malaysian population: results from the National Eye Survey 1996. Br J Ophthalmol 2002; 86: 951-956.

34 Li Z, Cui H, Liu P, Zhang L, Yang H, Zhang L. Prevalence and causes of blindness and visual impairment among the elderly in rural southern Harbin, China. Ophthalmic Epidemiol 2008; 15: 334-338.

35 Attebo K, Mitchell P, Smith W. Visual acuity and the causes of visual loss in Australia. The Blue Mountains Eye Study. Ophthalmology 1996; 103: 357-364.

36 VanNewkirk MR, Weih L, McCarty CA, Taylor HR. Cause-specific prevalence of bilateral visual impairment in Victoria, Australia: the Visual Impairment Project. Ophthalmology 2001; 108: 960-967. 